\title{
CONFERENCE REPORT: 'WHY TTIP? ON ITS RATIONALE, INSTITUTIONS AND SUBSTANTIVE CONSEQUENCES' (AMSTERDAM, 17 FEBRUARY 2015)
}

\author{
RAFAE MAŃKO*
}

On 17 February 2015 the University of Amsterdam Faculty of Law hosted a half-day workshop entitled Why TTIP? On Its Rationale, Institutions and Substantive Consequences The workshop was convened by Dr. Marija Bartl, LL.M. (Assistant Professor, Centre for the Study of European Contract Law, University of Amsterdam) and was institutionally organised by Access Europe - Centre for Contemporary European Studies, a joint research platform of the University of Amsterdam and the Vrije Universiteit in Amsterdam. The aim of the workshop was to provide a forum for critical reflection on the Transatlantic Trade and Investment Partnership (TTIP), which is currently being negotiated by the European Commission with the United States. The workshop focused on three aspects of the TTIP its rationale (first panel), its institutional setup (second panel) and its impact upon the rule of law in the EU (third panel).

The first session was opened by Dr. Marija Bartl, who explained the rationale of the workshop and gave the floor to the first speaker, Mr David Kleimann, LL.M. (Research Associate at the European Centre for International Political Economy, Brussels; Doctoral Researcher, Law Department, European University Institute). Mr Kleimann's paper was titled Is TTIP a 'normal' trade agreement? He argued that TTIP is indeed a normal, second-generation trade agreement, pointing out that the opposition to it is misconceived, as many similar agreements are already in force. However, admittedly a novelty of TTIP is its broad institutional framework.

The second paper was delivered by Dr. Ferdi de Ville (Senior Lecturer, Centre for EU Studies, University of Ghent) and was devoted to the Economic rationale for the TTIP. Dr. de Ville pointed out that the

DOI: 10.1515/wrlae-2015-0010

* Ph.D, Policy Analyst, European Parliamentary Research Service; External Fellow, Centre for the Study of European Contract Law, University of Amsterdam; r.t.manko@uva.nl. 
economic benefits of the TTIP for EU citizens, as calculated by the European Commission, would amount to an increase of purchasing power of EU citizens by approximately $€ 2.50$ per week ('one extra coffee every week'), and this would take place only by 2027 . Therefore, according to Dr. de Ville, it cannot be claimed that the rationale of TTIP is to bring more welfare to EU citizens ('growth and jobs'), but its actual driving force is simply the liberalisation of international trade, and hence it is mainly favourable to multi-national corporations which are staunch supporters of the agreement.

The discussion which followed the first panel focused on REA (regulatory equivalence assessment) as a form of simplified mutual recognition of standards between the US and EU, foreseen by the TTIP. It was underlined that the innovative aspect of TTIP is its institutional framework, unknown to earlier free trade agreements.

The second session was chaired by Dr. Joana Mendes (Senior Lecturer, Amsterdam Centre of European Law and Governance). The first speaker was Professor Alemanno (École des Hautes Etudes Commerciales de Paris), whose presentation was titled Institutional structure and democratic consequences of TTIP. He pointed out that the important issues of TTIP which should be the object of further research are, in particular, its nature, scope, political and democratic control, as well as balance of commitments between the EU and the US. In Professor Alemanno's view, the TTIP does not pose challenges to the democratic rule of law, because delegated acts adopted by the Commission on the basis of TTIP will be subject to scrutiny by the EP and Council during a 60 -day period before they enter into force.

The second paper in the second panel was delivered by Dr. Bartl and was a critical reply to the paper of Professor Alemanno. Dr. Bartl focused on the aspects of information, knowledge and power under the TTIP. She pointed out that the underlying rationale of TTIP is the EU's rivalry with BRICS (the trade bloc comprising Brazil, Russia, India, China and South Africa) and the removal of trade barriers. In her view, the TTIP is a challenge for the rule of law in the EU and in particular to public policies pursued by the EU and its Member States (e.g. in the fields of public health and consumer protection), because it will replace the EU's broad balancing of interests with a narrow economistic cost/benefit analysis. She expressed the fear that the American regulator OIRA (Office of Information and Regulatory Affairs), due to the fact that it applies a strict economic analysis, can gain an upper hand in the Regulatory Council established by TTIP.

The discussion following the second panel focused inter alia on the impact of TTIP for the system of sources of law in the EU. Some participants expressed the fear that TTIP will weaken the role of the European Parliament and strengthen the regulatory powers of the Commission.

The third session was chaired by Professor Martijn Hesselink (Centre for the Study of European Contract Law, Amsterdam). The first paper was delivered by Dr. Maria Weimer (Amsterdam Centre for European Law and Governance) and was titled TTIP and Public Health: The future of precaution in the $E U$. The speaker pointed out at the outset that the European precautionary principle, applicable in the field of public health, 
does not have an equivalent in US regulatory practice. She gave the example of the impact of neonicotinides upon bees. According to recent scientific evidence, this substance causes the mass death of bees. Therefore, it was banned by the EU in 2013. In contrast, it remains legal in the US, whose regulatory agency pointed out that the death of bees is caused by a number of factors, and the use of neonicotinides in agriculture is just one of them. In sum, according to Dr. Weimer, the TTIP will bring about a clash of two very different and incompatible regulatory cultures.

The final paper was delivered by Professor Harm Schepel (Brussels School of International Studies) and was titled TTIP and the Investor to State Dispute Settlement. Professor Schepel pointed out that ISDS (investor to state dispute settlement) mechanisms are normally foreseen in BITs (bilateral investment treaties) between rich, Western countries which export capital on the one hand, and poor, third-world countries which seek foreign investments. The rationale behind ISDS is the 'outsourcing of the rule of law', as Professor Schepel called it, meaning that disputes between the foreign investor and the local government are decided not by domestic courts (distrusted by the capital-exporting country), but by a panel composed of three arbitrators. One of them is appointed by the host country, a second one by the investor and the third is either appointed by joint agreement, or by the International Centre for Settlement of Investment Disputes (ICSID), which is part of the World Bank Group. Professor Schepel pointed out that ISDS arbitration decisions are usually biased in favour of investors. As an example, he cited the recent arbitration award in the case of Quasar de Valores SICAV SA et al v Russian Federation, which, in his view, favours foreign investors over the public policy of the host country. He also pointed out that most arbitrators are frequently reappointed and that they are paid extremely high remuneration (approximately €200.000 per case). In Professor Schepel's view, the ISDS mechanism in TTIP is fundamentally incompatible with EU law as interpreted by the CJEU in its case law (Joined cases C-120/06 P and C121/06 P FIAMM et al. v Council, C-399/11 Melloni, Opinion 2/13).

The discussion following the third panel focused on the (in)compatibility of the ISDS mechanism with EU law. 